\title{
KANT Y EL PADRENUESTRO
}

\author{
ROGELIO ROVIRA \\ Universidad Complutense de Madrid
}

\begin{abstract}
RESUMEN: En el esfuerzo por conciliar la tesis de que la oración, en tanto que culto interior y ritual de Dios, no es un deber religioso con el hecho de que Jesús ordenó y enseñó a rezar, Kant sostiene que el Padrenuestro es una oración que convierte en superflua toda oración, incluida ella misma. El análisis del sentido de esta afirmación, en apariencia parádojica, saca a la luz la tesis de Kant según la cual el Padrenuestro es una oración completamente moral e invita a reconstruir, siguiendo las indicaciones del filósofo, el significado moral de las siete peticiones contenidas en la oratio Domini. El Padrenuestro así interpretado aparece como el compendio de lo que Kant entiende por religión dentro de los límites de la mera razón.
\end{abstract}

PALABRAS CLAVE: Kant, Padrenuestro, religión, oración.

\section{Kant and the Our Father}

ABSTRACT: In the effort to reconcile the thesis according to which prayer, as an inner ritual service of God, is not a religious duty with the fact that Jesus commanded and taught to pray, Kant argues that the Our Father is a prayer that renders all prayer dispensable, including itself. The analysis of the meaning of this statement, seemingly paradoxical, brings to light Kant's thesis according to which the Our Father is a completely moral prayer and invites to rebuild, following the philosopher's suggestions, the moral significance of the seven petitions contained in the Lord's Prayer. The Our Father, thus interpreted, appears as the epitome of what Kant means by religion within the boundaries of mere reason.

KEY WORDS: Kant, Our Father, religion, prayer.

La religión es, para Kant, la consideración de nuestros deberes morales como mandamientos divinos. Sin duda, es la sola razón la que nos da a conocer los deberes morales y nos los impone. Pero el bien supremo que nuestra razón nos ordena perseguir es también, según enseña el filósofo, «el fin último de Dios en la creación del mundo» (KpV, AA 05: 130; cf. RGV, AA 06: 40)ํ․ Cumplir nuestros deberes morales equivale, por tanto, a servir a Dios. «La moral conduce ineludiblemente a la religión» (RGV, AA 06: 6), dice la conocida aseveración de Kant.

Es sabido que, según la concepción del filósofo, entre nuestros deberes morales o religiosos no se encuentra el deber de orar. La declaración de Kant al respecto no puede ser más tajante: «La oración, concebida como un culto interior y ritual de Dios y, por ello, como medio de gracia, es una ilusión supersticiosa (una fabricación de fetiches); pues es meramente la declaración de un deseo frente a un ser que en modo alguno necesita que el que desea le declare su íntima actitud fundamental, mediante la cual, por tanto, nada se hace y no se cumple, en

1 Sobre las abreviaturas empleadas para citar las obras de Kant, véase la nota al final del escrito. 
consecuencia, ninguno de los deberes que nos incumben como mandamientos divinos; de ahí que Dios no sea realmente servido» (RGV, AA 06: 194)2.

También es notoria la admiración que el filósofo de Königsberg sintió por la figura de Jesús, «el Maestro del Evangelio», como suele llamarlo. No le pudo pasar por ello inadvertido el hecho de que Jesús reconociera, como hace el propio Kant, que Dios no tiene necesidad de que el orante le declare sus deseos: «Vuestro Padre sabe lo que os hace falta antes de que lo pidáis» (Mt 6, 8). Y, sin embargo, Jesús, lejos de extraer de ello la consecuencia que saca Kant según la cual la oración no es un deber con el que se sirve a Dios, ordena a sus discípulos que recen y les enseña, justo a continuación de las palabras citadas, la oración que conocemos como el Padrenuestro (Mt 6, 9-13): «Vosotros orad así: "Padre nuestro que estás en el cielo, santificado sea tu nombre, venga a nosotros tu reino, hágase tu voluntad en la tierra como en el cielo, danos hoy nuestro pan de cada día, perdona nuestras ofensas, como también nosotros perdonamos a los que nos ofenden, no nos dejes caer en la tentación, y líbranos del mal”». (Una fórmula más breve se encuentra en Lc 11, 2-4).

En el esfuerzo por tratar de conciliar ambos puntos de vista: el de que la oración no es un deber moral ni divino y el de que el admirado "Maestro del Evangelio» ha mandado rezar el Padrenuestro, Kant no retrocede ante lo que parece presentarse como una paradoja. A su juicio, en efecto, el Padrenuestro es una oración que hace superflua toda oración, incluida ella misma. Cumplir el mandato de rezar el Padrenuestro habría de tener como consecuencia no tener ya el deber de rezar ninguna oración. Rezar el Padrenuestro sería, pues, cumplir un mandamiento que anula el deber de rezar. He aquí el modo en que el propio Kant enuncia esta paradoja, al menos aparente: «El Maestro del Evangelio ha expresado de un modo excelente el espíritu de la oración en una fórmula [a saber, el Padrenuestro] que hace a la vez prescindible la oración y, con ello, a sí misma (como letras)» (RGV, AA 06: 195).

¿No es, en verdad, contradictoria esta afirmación de Kant? ¿Cómo habría que entender, a la luz de esta declaración, las peticiones del Padrenuestro? Consideremos sucesivamente las respuestas que cabe encontrar a estas cuestiones a partir de las explicaciones del propio Kant.

\section{El Padrenuestro a la luZ de la distinción entre el espíritu y la letra de la ORACIÓN}

Ante todo plantéase la pregunta: ¿No es un puro absurdo sostener que estamos sometidos a un mandato, el de rezar el Padrenuestro, cuyo cumplimiento nos exime de estar sometidos al deber de orar, o mejor, nos muestra que no

2 Sobre la concepción kantiana del «servicio de Dios» (Gottesdienst) puede verse el artículo de BERnd DörfLINGer, «¿Cómo quiere Dios ser servido? El servicio de Dios en la filosofía de la religión de Kant», Éndoxa, 18 (2004), pp. 251-271. 
tenemos tal deber? ¿No es contradictorio admitir que, según lo que nos enseña el «Maestro del Evangelio», debemos recitar el Padrenuestro y, a la vez, que el cumplimiento de esa obligación nos libera de estar sometidos a ella, puesto que con esa recitación «no se cumple ninguno de los deberes que pesan sobre nosotros como mandamientos de Dios»? ¿No equivale esto a sostener la paradoja de que el Padrenuestro es una oración que se destruye a sí misma como oración?

Es claro que el único modo de que la afirmación kantiana no constituya una patente contradicción es admitir que cabe entender el término «oración» en más de un sentido. Y tal es, en efecto, lo que se desprende de las breves enseñanzas que Kant brinda sobre este asunto ${ }^{3}$.

Kant distingue expresamente, en primer lugar, lo que llama «el espíritu de la oración» (der Geist des Gebets) de "la letra de la oración» (der Buchstabe des Gebets)»(cf. RGV, AA 06: 195-197). Por espíritu de la oración se entiende una oración que se mantiene siempre en los límites de la mera razón y forma parte, por ello, de la «religión de la razón» o «religión moral». No ocurre, en cambio, lo mismo con la llamada letra de la oración, que cabe entender o bien contenida dentro del círculo de la religión de la razón o bien situada fuera de dicho círculo. De ahí que Kant distinga también, en segundo lugar, de manera acaso no tan explícita, pero sin duda inequívoca, la letra de la oración que forma parte de la «religión de la buena conducta de la vida» (Religion des guten Lebenswandels) de la letra de la oración que pertenece a la «religión de la solicitación de favor» (Religion der Gunstbewerbung) (cf. RGV, AA 06: 51). La letra de la oración puede estar, pues, o bien en conformidad con el espíritu de la oración o bien en oposición a dicho espíritu.

Este triple significado en que cabe entender el término «oración» es reflejo de la doble tarea que Kant asigna al filósofo de la religión. Como es sabido, en el Prólogo a la segunda edición de La religión dentro de los límites de la mera razón, Kant compara la religión revelada con una esfera que puede incluir en

3 Los principales lugares en los que KANT trata de la oración, y en los que a veces se refiere al Padrenuestro, son: Die Religion innerhalb der Grenzen der bloßen Vernunft (1793), AA 06: 195-198. Estas páginas retoman lo que el filósofo enseñó entre los años 1775-1784 en sus lecciones sobre filosofía moral: Moralphilosophie Collins, AA 27: 323-327 y 433-434 (cf. los lugares paralelos en la Moral Mrongovius, AA 27:1465-1469 y 1553-1554, y en la Moral Brauer, ed. Menzer, 122-129 y 269-270). A estos lugares hay que añadir la Reflexion 8092, AA 19: 637-638, que se data entre los años 1788-1790 y las enseñanzas de las lecciones sobre filosofía moral procedentes de los años 1793-1794 conocidas como la Metaphysik der Sitten Vigilantius, AA 27: 727-732. En el enciclopédico estudio de CoRnelio FABRo, La preghiera nel pensiero moderno, Roma, Edizioni di Storia e Letteratura, 1983, se dedican las pp. 198-209 a exponer la concepción kantiana de la oración. En el ensayo de UMBERTo REgINA, «La preghiera e l'autonomia della morale in I. Kant», Filosofia, 27 (1967), pp. 193- 222, se encuentran también algunas breves observaciones sobre la interpretación kantiana del Padrenuestro (pp. 204-205). Un estudio analítico y comparativo de las interpretaciones del Padrenuestro en pensadores del siglo xviII tales como Christian Langhansen, Johann Georg Hamann, Johann David Michaelis y el propio Immanuel Kant, se encuentra en Hanna Kauhaus, Vielfältiges Verstehen: Wege der Bibelauslegung im 18. Jahrhundert, Leipzig, Evangelische Verlagsanstalt, 2011, III.3, pp.128-158. 
sí la esfera más pequeña de la religión de la razón, y encarga al filósofo dos tareas: primera, determinar a priori la esfera de la religión de la razón; segunda, considerar alguna religión revelada para establecer si, como sistema histórico provisto de conceptos morales, concuerda con la religión de la razón o se halla en desacuerdo con ella. Con la determinación del llamado espíritu de la oración el filósofo de la religión cumple la primera de las tareas que le son encomendadas; con la discriminación de si la letra de una oración revelada está en acuerdo o en desacuerdo con el espíritu de la oración el filósofo lleva a cabo la segunda tarea que le es propia.

Pero, ¿cómo describe Kant cada una de las tres especies de oración que distingue? Expongamos de manera ordenada la enseñanza que el filósofo ofrece apenas ocasionalmente y de modo fragmentario. Tratemos así, primero, cada tipo de oración considerada en sí misma, esto es, respecto de su naturaleza específica y de su valor propio. Describamos luego cada clase de oración en relación con el orante, y esto, a su vez, en dos respectos: según cómo se le impone en cada caso el mandato de orar y según sea la disposición interior exigida para llevarlo a cabo. Y consideremos, en fin, el modo en que en cada especie de oración se vive la relación «ante Dios», de la que no cabe prescindir en ninguna forma de plegaria.

\subsection{El espíritu de la oración}

La oración, entendida según su espíritu, consiste en el deseo de servir a Dios mediante nuestras acciones u omisiones. La constante observancia de la ley moral es, en efecto, lo único en lo que, a tenor de la religión moral, puede consistir el servicio a Dios por parte del hombre (cf. RGV, AA 06: 103-104). Por ello puede definir Kant este primer significado de la oración en los siguientes términos: «El espíritu de la oración es un deseo cordial de ser grato a Dios en todo nuestro obrar y omitir, es decir, es la actitud fundamental (Gesinnung) que acompaña a todas nuestras acciones de llevarlas a cabo como si ocurrieran en el servicio de Dios» (RGV, AA 06: 194-195). Así, pues, aunque el espíritu de la oración en nada se distingue, por su contenido, de la moralidad, no puede reducirse enteramente a ella: es la moralidad misma enjuiciada en su necesaria relación con Dios; es, dicho de otro modo, la consideración de lo que habría de resultar de nuestro buen obrar; o todavía, con más precisón, es el deseo íntimo de lo que podemos esperar de nuestra buena conducta moral. De ahí que el espíritu de la oración tenga el valor de un fin en sí mismo, puesto que no busca otra cosa que la moralidad en nosotros sirviendo con ello a los fines Dios ${ }^{4}$.

4 Es importante advertir que, para Kant, la religión no se reduce a la moralidad. La moralidad, en efecto, conduce necesariamente a la idea de Dios y a entrar en relación «con la idea de Dios que la misma razón se hace» (MS, AA 06: 487), cuestión que es propia de la religión. Por esta razón, el espíritu de la oración tampoco se reduce en modo alguno al cumplimiento de los deberes morales. La oración, entendida según su espíritu, es propiamente, para Kant, oración, y no mera moralidad, ya que, como enseña el filósofo, consiste no solo en 
Se entiende entonces que el espíritu de la oración se imponga al orante como un deber en sentido estricto, pues no es sino el mismo imperativo de la moralidad considerado en su concordancia con «una voluntad moralmente perfecta (santa y buena), y al mismo tiempo todopoderosa» (KpV, AA 05: 129). A fuer de tal, la oración según su espíritu es necesaria y no puede ser sino incesante: el espíritu de la oración - escribe Kant citando unas palabras del Evangelio (Lc 18, 1) - "puede y debe tener lugar en nosotros "sin desfallecimiento"» (RGV, AA 06: 195). La única disposición adecuada en que semejante deber de orar puede cumplirse es, por tanto, la de la fe, esto es, la certeza de que la aspiración a servir a Dios mediante la buena conducta será indefectiblemente cumplida. El deseo de ser moralmente bueno, «vivificado mediante la idea de Dios» (RGV, AA 06: 195-196), es, en efecto, al decir de Kant, «un deseo que, si es serio (activo), él mismo produce su objeto (llegar a ser una persona agradable a Dios)» (RGV, AA 06: 195). El orante puede, pues, «estar seguro de la exaudibilidad» de la oración que nace de la actitud moral fundamental (RGV, AA 06: 196).

En el espíritu de la oración, la relación «ante Dios» se concibe como la relación con una mera idea que sirve para dar vigor al deseo moral (cf. MS, AA 06: 487). Con esta oración no se busca, pues, influir sobre Dios, sino solo sobre uno mismo: con su deseo de servir a Dios, el orante, escribe Kant, «solo busca obrar sobre sí mismo (para vivificar sus actitudes fundamentales mediante la idea de Dios)»(RGV, AA 06: 195). De ahí que no resulte paradójico el hecho de que se pueda orar según el espíritu sin estar por completo convencido de la existencia de Dios. Así lo afirma, en efecto, el propio Kant: según el espíritu, «una oración puede tener lugar con plena sinceridad, aun cuando el hombre no se arrogue poder afirmar solemnemente, como plenamente cierta, la existencia de Dios» (RGV, AA 06: 195).

\subsection{La letra de la oración en conformidad con el espíritu de la oración}

«El espíritu de la oración» — señala Kant- «tiene lugar sin ninguna letra» (V-Mo/Collins, AA 27: 324). En consecuencia, por «letra de la oración», u «oración vocal», según la denominación tradicional, hay que entender, en general, el revestimiento con palabras de un deseo expresado ante Dios. Es claro que el orante puede o bien manifestar sus íntimos deseos con sus propias palabras o bien hacer suyos los deseos recogidos en una fórmula recibida. En este último

el cumplimiento de los deberes morales, sino en el deseo cordial de ser grato a Dios mediante el cumplimiento de tales deberes. En el ensayo de David H. ChandLeR, «Kant on Prayer» (en Stefano Bacin, Alfredo Ferrarin, Claudio La Rocca, Margit Ruffing (Hrsg.), Kant und die Philosophie in weltbürgerlicher Absicht. Akten des XI. Kant-Kongresses 2010. Pisa 22-26 Maggio 2010, im Auftrag von Kant-Gesellschaft e.V. Berlin-New York, Walter de Gruyter, 2013, Bd. 2 , pp. 847-858), se contienen expresiones que pueden dar lugar a equívocos en este punto crucial, como cuando se afirma que «la oración, pues, no es nunca buena en sí misma», o que «lo que la oración tendría que ser, "el espíritu de la oración", es moralidad», o que "el peligro al orar es que la oración no es nunca la cuestión importante» (p. 848). 
caso, que es el que únicamente interesa considerar ${ }^{5}$, la letra de la oración viene a ser, como la define Tomás de Aquino, «intérprete de nuestro deseo ante Dios (desiderii nostri interpres apud Deum)» (Summa Theologiae, II-II, q. 83, a. 9 c.). Y es claro que, según la enseñanza de Kant, en este punto solo caben dos posibilidades: o que el deseo expresado por la letra de una oración esté de acuerdo con el espíritu de la oración o que no se pliegue de ninguna manera a dicho espíritu.

La oración cuya letra se atiene al espíritu de la oración no puede ser sino una fórmula en la que «no se encuentra nada más que el propósito de la buena conducta de la vida» (RGV, AA 06: 195). En este sentido, el contenido de los deseos que se expresan en esta especie de plegaria tiene que ser necesariamente universal, y no meramente privado e individual, condición que solo cumple el deseo de una conducta moralmente irreprensible. Así lo declara el propio Kant: «El objeto de la oración debe ser universal y no estar determinado, para que la sabiduría de Dios pueda brillar del modo máximamente conveniente. Pero universal es cuando pedimos la dignidad de todo buen obrar que Dios esté dispuesto a concedernos»(V-Mo/Collins, AA 27: 326). Dado que Dios ve inmediatamente la actitud moral del orante y no necesita que este se la haga saber mediante el uso de palabras, la oración vocal de esta índole es solo un medio para despertar en el que ora el respeto a la ley moral. Mediante la letra de la oración, escribe Kant en una de sus Reflexiones, «las ideas oscuras y confusas presentes en el alma se vuelven más claras o se les comunica un grado mayor de vivacidad, con lo cual se otorga mayor efectividad a los fundamentos de determinación para la virtud, etc.» (Refl 8092, AA 19: 637). Así, pues, la letra de la oración que persigue un fin moral se subordina, como medio, al espíritu de oración en tanto que fin. La letra de la oración en conformidad con el espíritu de la oración tiene, en efecto, al decir de Kant, «solo el valor de un medio para reavivar repetidamente en nosotros mismos aquella actitud fundamental» (RGV, AA 06: 195-196; cf. VARGV, AA 23: 124), esto es, la de agradar a Dios en todas nuestras acciones y omisiones. «La oración posee la bondad de un medio», reitera inequívocamente el filósofo (V-Mo/ Collins, AA 27: 325).

A fuer de medio, la letra de la oración que cabe llamar «moral» es objetivamente innecesaria, aunque acaso a alguno le pueda ser subjetivamente necesaria «para fortalecer su ánimo y robustecer sus disposiciones a actuar» (V-Mo/ Collins, AA 27: 324). De ahí que enseñe Kant: «Precisamente por ello tampoco puede ser un deber para todos, ya que un medio solo puede ser prescrito a quien lo necesita para ciertos fines, pero ni con mucho tienen todos necesidad de este medio» (RGV, AA 06: 196-197). El mandato de orar según la letra, propiamente entendido, habría que contarlo, por tanto, entre los consilia, esto es,

5 Todavía hemos de limitar más nuestro tema: se tratará tan solo de la oración privada, no de la oración pública. Sobre esta última puede consultarse el ya citado ensayo de UMBERTO REGINA, «La preghiera e l'autonomia della morale in I. Kant», esp. pp. 209-218. 
entre los imperativos de la prudencia, pues seguirlo no es en absoluto necesario. Como dice Kant en una de sus lecciones sobre filosofía moral, «la letra solo es necesaria respecto de nosotros, en la medida en que despierta en nosotros el espíritu de la oración»(V-Mo/Collins, AA 27: 326). Por ello, lejos de mandarnos orar sin cesar, la letra de la oración que busca reavivar la moralidad en el que ora está llamada a desparecer. También esto lo declara el propio filósofo: «Antes bien, es solo mediante una continua purificación y elevación de la actitud moral fundamental como se ha de trabajar en que llegue a vivificarse suficientemente en nosotros este espíritu de la oración, y que su letra pueda al cabo desaparecer (al menos en lo que a nosotros concierne)» (RGV, AA 06: 197). La necesaria desaparición a que está abocada esta clase de oración vocal muestra eo ipso la exaudibilidad de esta misma oración. Esta oración puede, en efecto, llevarse a cabo con fe, esto es, con la certeza de que el deseo que se implora será realizado. Como reconoce expresamente Kant, «solo semejante oración es exaudible, pues es moral y, por tanto, adecuada a la sabiduría de Dios» (V-Mo/ Collins, AA 27: 326).

Al igual que en el espíritu de la oración, en la letra de la oración que se atiene a dicho espíritu la relación «ante Dios» es también, en rigor, la relación con una mera idea que sirve para fortalecer el deseo moral. Ahora bien, Kant no deja de señalar el peligro que sobre este punto se cierne sobre la letra de la oración. Este peligro nace de la paradoja que supone pretender hablar con Dios. «Solo podemos hablar con aquel que podemos ver;» - afirma Kant"pero puesto que no podemos ver a Dios, sino solo creer que Dios existe, resulta completamente absurdo hablar con alguien a quien no se ve» (V-Mo/ Collins, AA 27: 323-324). La admisión de la existencia de Dios como postulado de la razón pura práctica, aunque nos lleva a reconocer el carácter personal de este ser, en modo alguno nos autoriza a admitir su presencia como interlocutor ante nosotros: «La existencia de la divinidad no está demostrada, sino que es postulada, y por tanto solo puede servir para lo que la razón está obligada a postular» (Refl 8092, AA 19: 637). En consecuencia, la forma misma de la letra de la oración, en tanto que alocución (Anrede) dirigida a Dios, impone al orante la aceptación de que el ser supremo está personalmente presente, o al menos obrar como si estuviese convencido de ello. Lo cual muestra, en definitiva, que en la letra de la oración «no puede encontrarse la sinceridad de un modo tan perfecto» (RGV, AA 08: 195) como en el espíritu de la oración, en el que el orante ni siquiera se ve forzado a suponer la existencia de Dios, no digamos ya a afirmarla con certeza. Kant ilustra incluso la aludida falta de sinceridad con una observación psicológica: el azoramiento y hasta la vergüenza que experimenta un orante cuando es sorprendido, si no rezando en voz alta, al menos en actitud de estarlo. Su confusión nace de que se le descubre haciendo algo para lo que no tiene razón suficiente: el orante parece suponer que está delante de alguien a quien no puede en absoluto ver (cf. RGV, AA 08: 195). 


\subsection{La letra de la oración en oposición al espíritu de la oración}

La enseñanza de Kant sobre el espíritu de la oración y la letra que se atiene a dicho espíritu hace fácil ahora comprender que, según el filósofo, la oración cuya letra está en disconformidad con el espíritu de la oración consistirá en la petición a Dios de un «favor». Este favor puede referirse, según las indicaciones de Kant, o bien al logro de un deseo de índole no moral o bien a la consecución de un deseo moral, "pero que solo fuera posible mediante un influjo sobrenatural (o, cuando menos, solo de ahí lo esperásemos, porque no quisiésemos esforzarnos nosotros mismos por conseguirlo, como, por ejemplo, la conversión, el revestirse del hombre nuevo, que se llama el nacer de nuevo)» (RGV, AA 06: 196). En ambos casos la oración se convierte en un culto ritual de Dios, en un presunto «medio de gracia» con el que el orante pretende, en palabras del propio Kant, «utilizar, mediante un deseo suscitado en él mismo y por sí mismo, el poder divino para sus propios propósitos» (RGV, AA 06: 196). De ahí el duro y tajante juicio del filósofo sobre la naturaleza y el valor de esta especie de oración: «Es una ilusión supersticiosa (una fabricación de fetiches) (ein abergläubischer Wahn, ein Fetischmachen)» (RGV, AA 06: 194).

$\mathrm{Al}$ entregarse a esta clase de oración, el orante no solo no cumple «ninguno de los deberes que nos incumben como mandamientos divinos» (RGV, AA 06: 194), sino que ni siquiera se atiene a ciertas regulae o imperativos de la habilidad. Quien pide a Dios la obtención de un deseo no moral, o de un deseo moral que no reclama de su parte ninguna cooperación con el bien, se aparta eo ipso de la sabiduría divina, que acaso ha dispuesto como mejor para nosotros algo distinto de lo que deseamos. Por eso advierte Kant: «Es también una ilusión absurda y a la vez presuntuosa tratar, mediante la insistente inoportunidad del ruego, de que Dios se aparte de los planes de su sabiduría (para nuestro provecho presente)» (RGV, AA 06: 196). La incertidumbre respecto de lo que en definitiva haya de resultar de nuestras demandas privadas no puede sino ocasionar temor en el orante: "Yo mismo me atemorizaría» —se lee en las lecciones de Kant sobre filosofía moral — «si Dios hubiera de atender mi ruego particular, pues no podría saber si yo mismo habría pedido mi propia desgracia» (V-Mo/ Collins, AA 27: 325). Se entiende entonces que semejante oración no pueda llevarse a cabo con fe, esto es, con la certeza de que ha de ser escuchada. Kant lo asevera expresamente tanto en el caso del deseo no moral como en el del deseo moral que no exige un cambio interior. Respecto del primero escribe: «No podemos, por tanto, tener con certeza por exaudible ninguna oración que tenga un objeto no moral, es decir, no podemos pedir algo así con fe» (RGV, AA 06: 196). Respecto del segundo señala que «es tan incierto que Dios halle conforme a su sabiduría suplir de modo sobrenatural nuestra imperfección (de la que somos culpables), que más bien hay motivo para esperar lo contrario» (RGV, AA 06: 196). A ese motivo se ha referido de modo expreso Kant comentando precisamente una de las enseñanzas de Jesús contenidas en la parábola de los talentos (cf. Mt 25, 29): «A quien deja sin utilizar la disposición natural al bien que se halla en la naturaleza humana (como un talento que se le ha confiado), 
con perezosa confianza en que de otro modo un influjo moral superior completará la calidad y perfección moral que le falta, le amenaza con que ni siquiera el bien que pueda haber hecho por disposición natural le será tenido en cuenta a causa de esta negligencia» (RGV, AA 06: 161).

En la letra de la oración que no se atiene al espíritu de la oración la relación «ante Dios» es, al decir de Kant, la relación con una idea impura de Dios, como es «la idea de que Dios mismo hace del principio de la felicidad la condición suprema de sus mandamientos». Kant llega incluso a afirmar que esta forma de oración puede llevar a la hipocresía (Heuchelei), pues el orante se dice interiormente: «Si oro a Dios, esto no puede en ningún caso dañarme; porque si él ahora no es bueno, yo he hecho bastante el bien; pero si lo es, entonces me ayudará» (Refl 8092, AA 19: 637-638). Cuando menos, esta falsa idea del ser divino, este ídolo, en el rigor de los términos, lleva al hombre a desatender su propia condición moral, según sostiene el filósofo, «al lisonjearse o bien de que Dios puede hacerle eternamente feliz sin que él mismo tenga necesidad de llegar a ser un hombre mejor (mediante el perdón de sus culpas), o bien, si esto no le parece posible, que Dios puede hacerle un hombre mejor sin que para esto tenga él mismo que hacer otra cosa más que pedirlo» (RGV, AA 06: 51).

\subsection{El Padrenuestro como oración plenamente moral}

A la luz de estas distinciones sobre las distintas especies de oración, se entiende la concepción general que se formó Kant del Padrenuestro y se resuelve lo que en principio parecía una paradoja, a saber, que no haya el deber moral ni divino de orar y que, sin embargo, «el hijo de Dios», «la idea personificada del principio bueno» (RGV, AA 06: 60), nos haya ordenado rezar una determinada oración.

En efecto, la tesis general de Kant sobre el Padrenuestro es que se trata de «una oración plenamente moral» (ein ganz moralisches Gebet) (V-Mo/Collins, AA 27: 434), de una oración, por tanto, que es puro reflejo sensible del espíritu de la oración.

A esta tesis general cabe añadir, como complemento suyo, que el Padrenuestro es, según Kant, modelo de toda oración moral tanto por su origen como por su forma y por su contenido. La oración enseñada por Jesús nace de «la conciencia de nuestra fragilidad» (RGV, AA 06: 195) a la hora de cumplir la ley moral. No tiene, pues, su origen, como en el caso de la oración que se opone al espíritu de la oración, en la pretensión de querer «ser una tentación de Dios (Versuchung Gottes), por cuyo medio pretendemos mover a Dios a satisfacer nuestros deseos» (V-Mo/Collins, AA 27: 325-326). Asimismo, ya en la concisión de su forma, el Padrenuestro revela cuán alejado se halla de las «oraciones verbosas» (wortreiche Gebete) (V-Mo/Collins, AA 27: 324) en que suelen convertirse las plegarias no morales. Y respecto, en fin, de su contenido, en la fórmula del Padrenuestro, enseña Kant, «no se encuentra nada más que el propósito de la buena conducta de la vida» (RGV, AA 06: 195). El Padrenuestro, en efecto, se contenta, al decir del filósofo, con referirse a «lo más perentorio de nuestras necesidades» (das nothwendigste unsrer Bedürfniße) y a «las disposiciones morales fundamentales» (moralische Gesinnungen) (V-Mo/Collins, AA 27: 324-325). 
Se entiende entonces que, según Kant, cumplir con el mandato de rezar la fórmula del Padrenuestro no pueda por menos de remitirnos a aquello que las palabras reflejan y terminar por hacer superflua toda recitación de oraciones y aun la del mismo Padrenuestro. Rezar el Padrenuestro es cumplir un consilium que tiene como fin vivificar el propósito de llevar a cabo nuestros praecepta concebidos como mandatos divinos. El mandato de rezar el Padrenuestro sería, dicho de otro modo, un imperativo hipotético, concretamente, un imperativo de la prudencia - si es que hubiera en verdad semejantes imperativos- puesto enteramente al servicio del cumplimiento del imperativo categórico de la moralidad considerado en su necesaria relación con el querer absolutamente santo y omnipotente de Dios. Una vez vivificada de veras la voluntad de someternos a ley moral y servir así a Dios, cabe desprenderse del medio utilizado para ese propósito. Por eso pudo Kant escribir las ya citadas palabras, que, como ahora se ve, no encierran paradoja alguna: «El Maestro del Evangelio ha expresado de un modo excelente el espíritu de la oración en una fórmula que hace a la vez prescindible la oración y, con ello, a sí misma (como letras)» (RGV, AA 06: 195).

El fundamento último de la disolución de lo que en principio parecía una paradoja se halla, como se ve, en el carácter de oración moral que Kant atribuye a la plegaria que enseñó Jesús. Pero, ¿es realmente el Padrenuestro una oración plenamente moral? ¿No se encuentra en su letra peticiones que van más allá del «propósito de la buena conducta de la vida», como parece evidente en la petición del "pan nuestro de cada día» y acaso en la petición de la santificación del nombre de Dios o en la de la venida del reino de Dios? ¿Cómo justifica Kant, en su interpretación de las peticiones del Padrenuestro, el carácter enteramente moral de esta oración?

\section{Las Peticiones del PadRenUestro SEgÚn El Espíritu de la oración}

En vano se buscará en las obras de Kant un comentario explícito de las siete peticiones contenidas en el Padrenuestro. En rigor, el filósofo solo considera de modo expreso la petición del pan nuestro de cada día, ya que es acaso la súplica que, en principio, parece oponer más dificultad a la consideración de la oratio Domini como una oración moral. No obstante, las muchas referencias que el pensador de Königsberg hace en su obra a conceptos propios de la religión cristiana permiten reconstruir, en líneas generales, una interpretación moral de todas las peticiones del Padrenuestro como oración cuya letra se atiene plenamente al llamado «espíritu de la oración».

Según esa interpretación, cabe distribuir en dos grupos las peticiones del Padrenuestro. El primer grupo abarcaría las tres primeras peticiones, las cuales no expresarían sino el deseo, vivificado por medio de la idea de Dios, de llevar a cumplimiento el fin de la vida moral. El segundo grupo contendría las cuatro restantes peticiones, las cuales serían manifestación del deseo, alentado 
mediante la idea del ser divino, de que se den los medios necesarios para la realización del fin de la vida moral.

\subsection{Las tres primeras peticiones}

Mirado a esta luz, las dos primeras peticiones del Padrenuestro se refieren al objeto supremo de la razón pura práctica. Mediante la súplica: «Santificado sea tu nombre», el orante pide, como es obvio, que Dios sea honrado. Ahora bien, "el honor de Dios (die Ehre Gottes) consiste», al decir de Kant, "en la observancia de sus mandatos»(V-Met-K2/Heinze, AA 28: 810). En efecto, según declara el filósofo en su segunda Crítica, «nada honra más a Dios que lo más apreciable en el mundo, el respeto por su mandato, la observancia del santo deber que nos impone su ley»(KpV, AA 05: 131). Lo que en el terreno de la moral es el objeto único del respeto es también, en el terreno de la religión, el objeto único del honor y la adoración. Así lo declara el propio filósofo: "Si la moral reconoce en la santidad de su ley un objeto del máximo respeto, en el plano de la religión presenta, en la causa suprema que ejecuta esas leyes, un objeto de adoración, y aparece en su majestad» (RGV, AA 06: 6-7). Cabe, pues, decir que pedir la santificación del nombre de Dios no es otra cosa, a tenor de estas indicaciones de Kant, que vivificar, por medio de la consideración de la perfección de Dios, el deseo de plegarse al bien supremo más elevado (supremum): la virtud, esto es, el primer elemento que constituye el bien supremo consumado (consummatum) del querer de los seres racionales finitos.

Es doctrina conocida de Kant que el bien supremo del querer de semejantes seres no está completo si falta su otro elemento necesario, la felicidad. En consecuencia, con la petición: «Venga a nosotros tu reino», el orante suplica que con su obrar moral se enlace necesariamente ese segundo elemento del bien supremo y obtenga así la felicidad merecida. Las siguientes palabras de Kant corroboran inequívocamente el sentido moral de la segunda petición del Padrenuestro: "La doctrina moral cristiana completa esta falta (del segundo elemento imprescindible del bien supremo) mediante la representación del mundo, en el que los seres racionales se consagran a la ley moral con toda el alma, como un reino de Dios (Reich Gottes), en el cual la naturaleza y la moralidad llegan a una armonía, extraña a cada una de ellas por sí misma, por medio de un creador santo, que hace posible el bien supremo derivado»(KpV, AA 05: 128, cf. SF, AA 07: 72). Pedir la venida del reino de Dios equivale, por tanto, según esta interpretación de Kant, a vivificar, por medio de la idea de un ser santo, benévolo y justo, el deseo de obtener la felicidad de la que uno se ha hecho moralmente digno y lograr así el bien supremo completo ${ }^{6}$.

6 En una de las anotaciones manuscritas póstumas de Kant se lee: «El reino de Dios sobre la tierra: este es el destino último del hombre. Deseo (venga tu reino)» (Refl 1396, AA 15: 608). Sobre la amplitud del concepto kantiano de «reino de Dios» puede verse el ensayo 
Si se ponen en relación ciertas observaciones de Kant, en verdad escasas, con determinadas doctrinas centrales del filósofo se puede inferir que la tercera petición del Padrenuestro se refiere a los motivos (Triebfedern) o fundamentos determinantes (Bewegungsgründen) de la razón pura práctica. Es sabido, en efecto, que, según la enseñanza de Kant, para ser moralmente bueno no basta cumplir con lo mandado por la ley moral. Es menester cumplirlo precisamente porque es mandado por la ley moral. Escribe, en efecto, el filósofo: «Lo esencial de todo valor moral de las acciones se halla en que la ley moral determine inmediatamente la voluntad» (KpV, AA 05: 71). Y tal parece ser, en efecto, lo que expresa la petición: «Hágase tu voluntad en la tierra como en el cielo». En una de las lecciones de Kant sobre filosofía moral podemos leer: «¿Qué significa alabar a Dios? Representarse vivamente la grandeza de Dios como un fundamento determinante (Bewegungsgrund) de nuestra voluntad de vivir según la voluntad divina (dem göttlichen Willen gemäß zu leben). El esfuerzo por contemplar la perfección de Dios pertenece necesariamente a la religión, que debe proporcionar fuerza y vigor a nuestra voluntad de vivir según la santa voluntad de Dios» (V-Mo/Collins, AA 27: 336). Pedir que se haga la voluntad de Dios en la tierra y en el cielo, pedir, pues, que nuestra voluntad se pliegue a la santa voluntad de Dios, no es sino vivificar, mediante la representación de la perfección de Dios, el deseo de que nuestras acciones no solo sean conformes al deber (pflichtmässig), sino que sobre todo sean hechas por deber (aus Pflicht) (cf. M9S, AA 06: 391), o, equivalentemente, que tengan como fundamento de determinación el mismo querer de Dios, el «único santo (der allein Heilige)» (KpV, AA 05: 131). Acaso teniendo presentes las palabras de Jesús según las cuales «el que acepta mis mandamientos y los guarda, ese me ama» (Jn 14, 21), pudo enseñar Kant que «amar a Dios en la práctica significa cumplir gustosamente (gern) sus mandatos porque son dignos de amor (liebenswürdig)» (V-Mo/Collins, AA 27: 335; cf. KpV, AA 05: 83).

$\mathrm{Al}$ estudiar Kant en su libro sobre la religión la necesidad de instituir un pueblo moral de Dios, escribe rememorando las tres primeras súplicas de la oración de Jesús: «El deseo de todos los hombres de buena voluntad (Wohlgesinnten) es, pues, "que venga el reino de Dios, que suceda su voluntad en la tierra” (RGV, AA 06: 101).

\subsection{La cuarta petición: la petición del pan cotidiano}

La cuarta petición del Padrenuestro: «Danos hoy nuestro pan de cada día», es la que en principio parece oponer más resistencia a ser interpretada en sentido moral. Kant, sin embargo, considera que esta petición no es óbice para seguir afirmando, según sus propias palabras, que el Padrenuestro «es una oración plenamente moral, aun cuando pidamos por el pan de cada día» (V-Mo/ Collins, AA 27: 434). La justificación que de esta tesis propone el filósofo sigue

de Giovanni B. Sala, «Das Reich Gottes auf Erden. Kants Lehre von der Kirche als "ethischem gemeinen Wesen"», en Norbert Fischer (Hrsg.), Kants Metaphysik und Religionsphilosophie, Hamburg, Felix Meiner, 2004, pp. 225-264. 
un doble camino, que a fin de cuentas resulta convergente. Cabe, en efecto, interpretar que la petición del pan no expresa en absoluto un deseo humano o bien que enuncia un deber y, por tanto, un deseo moral. Pero en ambos casos, el ruego por el pan diario se entiende como la súplica por que no falte uno de los medios positivos necesarios para la realización del fin de la vida moral.

Kant enseña que la naturaleza humana puede ser considerada desde tres puntos de vista: respecto de su animalidad, y en este aspecto el hombre aparece como ser viviente; respecto de su humanidad, y a este viso el hombre se muestra como un ser viviente que es, a la vez, racional; y respecto de su personalidad, y desde este punto de vista el hombre se presenta como un ser viviente racional que es también susceptible de imputación moral (cf. RGV, AA 06: 126). Es claro que las tres primeras peticiones del Padrenuestro tratan al hombre en su personalidad: son expresión del deseo de que se cumpla el destino moral al que está llamado. La cuarta petición, sin embargo, concierne al hombre respecto de su animalidad. Pero adviértase que el carácter animal del hombre puede, a su vez, examinarse desde dos perspectivas: en sí mismo o como fuente de deberes.

La petición del pan de cada día, en tanto que referida a la naturaleza animal del hombre en sí misma considerada, no es propiamente un deseo humano, sino, más bien, expresión de la pura naturaleza. El deseo propiamente humano, propiamente racional y, por tanto, previsor, sería pedir el pan para todos los otros días. Kant explica este asunto de manera paladina: «Incluso el deseo del medio de conservación de nuestra existencia (el pan) para un día, dado que no está expresamente referido a la continuación de esta existencia, sino que es el efecto de una necesidad meramente animal que sentimos, es más un reconocimiento de aquello que la naturaleza quiere en nosotros que una deliberada petición particular de aquello que el hombre quiere; tal sería la petición del pan para los demás días, que aquí queda excluida con bastante claridad» (RGV, AA 06: 195). No es entonces de extrañar que este deseo que la naturaleza suscita en nosotros no haya de ser cumplido siempre por la sabiduría divina. Escribe Kant, en efecto: «Pues aunque la petición se limite al pan para el día de hoy, nadie puede estar seguro de su exaudibilidad, esto es, de que esté necesariamente ligado con la sabiduría de Dios el concederle lo que pide; puede acaso concordar mejor con ella dejarlo morir hoy de esta carencia» (RGV, AA 06: 196).

Pero la petición del pan de cada día puede también juzgarse como expresión del deseo de que se cumpla un deber fundado en la naturaleza animal del hombre. En La metafísica de las costumbres Kant enseña, en efecto, que «el primer deber del hombre para consigo mismo en calidad de su animalidad es la conservación de sí mismo en su naturaleza animal»(M९S, AA 06: 421). No es por ello extraño que, según los apuntes de las lecciones sobre filosofía moral legados por Johann Friedrich Vigilantius, el filósofo haya enseñado lo siguiente sobre la petición del pan cotidiano: «Este deseo es en sí mismo, sin embargo, un deseo físicamente necesario, y el vivir es un deber. Es de esperar que Dios ampare nuestro deseo de vivir, no sin fundamento cabe esperarlo, por tanto, de la bondad de Dios, puesto que solo incluye lo necesario» (V-MS/ Vigil, AA 27: 728). 
Por tanto, la petición del pan nuestro de cada día o no es expresión de un deseo propiamente humano, y en consecuencia con ella no se tienta a Dios en modo alguno; o es manifestación de un deseo que busca el cumplimiento de un deber, y es por ello petición de un deseo moral. Pedir el pan cotidiano, deseo que, como dice Kant, «denuncia más la frugalidad que la preocupación por el alimento» (V-Mo/Collins, AA 27: 434), vale tanto como rogar por que se dé el medio positivo imprescindible para cumplir el fin de la vida moral: mantenerse en la existencia. Con ese ruego no se trata de solicitar ningún «favor». De ahí que esta petición no solo no esté de más en la oración moral del Padrenuestro, sino que no pueda faltar en la plegaria que es expresión literal del espíritu mismo de la oración.

\subsection{Las tres últimas peticiones}

Kant no podría por menos de reconocer, aunque, ciertamente, no lo haya declarado así de modo expreso, que quien reza las tres últimas peticiones del Padrenuestro es eo ipso consciente de una verdad fundamental, a saber, en palabras del propio filósofo, que «el primer bien verdadero que el hombre puede hacer es salir del mal, el cual no ha de buscarse en las inclinaciones, sino en la máxima invertida y, por lo tanto, en la libertad misma» (RGV, AA 06: 58). El estado moral del hombre no es, en efecto, como enseña Kant, una res integra, «sino que debemos empezar por expulsar al mal de la posesión en la que ya ha tomado sitio (lo que no podría haber hecho sin que nosotros lo hubiésemos admitido en nuestra máxima)» (RGV, AA 06: 58). Cabe decir, en efecto, que las tres últimas peticiones del Padrenuestro conciernen a la inexcusable tarea moral que todo hombre ha de emprender: luchar contra el mal que habita en su naturaleza. La remoción del obstáculo que el mal supone -ya en sí mismo algo moralmente bueno- es de este modo un medio necesario negativo para la consecución del fin de nuestra vida moral.

Es tesis famosa de Kant que «el hombre es malo por naturaleza» (RGV, AA 06: 32), es decir, que la naturaleza humana está entretejida de un mal que el filósofo califica de «radical». Mirado más de cerca, Kant atribuye la maldad al hombre en tres sentidos distintos, aunque mutuamente relacionados, a tenor de los tres significados diferentes, pero conexos, que cabe descubrir en la expresión «mal radical» ${ }^{7}$. Aunque Kant no ha dejado nada dicho sobre el asunto, no es forzar su pensamiento, sino más bien completarlo con fidelidad, entender que las tres últimas peticiones del Padrenuestro se refieren respectivamente a cada uno de los tres sentidos en que se atribuye la maldad al hombre.

7 Los tres sentidos de la expresión «mal radical» de que se trata a continuación han sido claramente puestos de relieve y explicados magistralmente por LEONARDo RoDRíGUEz DuPLÁ en su ensayo: “¿Qué es el mal radical?», Cuadernos salmantinos de filosofía, XXXII (2005), pp. 271-278. Cf. también de este autor su excelente estudio "Kants Lehre vom radikal Bösen», Jahrbuch für Religionsphilosophie, 6 (2007), pp. 97-122. 
El hombre es malo por naturaleza, en primer lugar, porque su actitud fundamental (Gesinnung) es mala, ya que desde el origen, en un acto fuera del tiempo del que no se guarda memoria, ha adoptado como pauta de su conducta la máxima invertida «de hacer de los motivos del amor a sí mismo y de sus inclinaciones la condición de la observancia de la ley moral, cuando es más bien esta última, en tanto que la condición suprema de la satisfacción de lo primero, la que debería ser acogida como motivo único en la máxima universal del albedrío» (RGV, AA 06: 36). En razón de este mal radical o peccatum originarium, como Kant lo llama, el hombre ha contraído una culpa innata y, en rigor, infinita, que le lleva a cometer innumerables acciones conformes a la máxima pervertida (peccata derivativa) (cf. RGV, AA 06: 31, 38 y 72). Por ello, como escribe el filósofo, "todo hombre tendría que esperar un castigo infinito y la exclusión del reino de Dios» (RGV, AA 06: 72). No obstante, todas esas culpas no han podido erradicar en modo alguno la disposición originaria del hombre al bien. En consecuencia, interpretando el pensamiento de Kant, habría que decir que el «Maestro del Evangelio», al enseñarnos a pedir a Dios: "perdona nuestras ofensas como también nosotros perdonamos a los que nos ofenden", nos insta a reconocer nuestra culpa, a alejarnos del mal y a emprender la tarea de mejorarnos moralmente. Pedir a Dios el perdón no es en modo alguno solicitarle un favor, ni tampoco expresar un deseo moral que no requiere de nosotros un cambio de actitud fundamental. Este punto lo deja muy claro la condición que el Padrenuestro pone para poder ser perdonados: que perdonemos nosotros a los que nos ofenden. Solo llevar a cabo ese esfuerzo de mejora moral, simbolizado por nuestro propio perdón a los otros, nos permite esperar —en modo alguno merecer ni mucho menos exigir- el perdón divino de nuestras culpas. Kant ha visto en esta verdad una característica propia de la enseñanza de Jesús: «En cambio, según la religión moral (tal es, entre todas las religiones públicas que ha habido, solamente la cristiana), es un axioma que cada cual debe hacer cuanto esté en sus fuerzas para llegar a ser un hombre mejor, y solo entonces, cuando no ha enterrado su talento congénito (Lc 19, 12-16), cuando ha utilizado la disposición originaria al bien para convertirse en un hombre mejor, puede esperar que lo que no está en su poder sea suplido por medio de una cooperación más alta» (RGV, AA 06: 51-52).

$\mathrm{El}$ acto inmemorial por el que el hombre ha adoptado la máxima invertida no ha podido por menos de afectar gravemente a la facultad humana de apetecer. El hombre es así malo por naturaleza, en segundo lugar, porque habita en él una propensión natural (natürlicher Hang) al mal moral, es decir, porque en su facultad de apetecer se halla «el fundamento subjetivo de la posibilidad de la desviación de las máximas respecto de la ley moral» (RGV, AA 06: 29). El hombre, que no es nunca inocente, ha de contar, pues, con este mal radical, con esta propensión que encuentra en su naturaleza. Como expresión de este caer en la cuenta de nuestra debilidad, impureza y corrupción (cf. RGV, AA 06: 29-30) hay que entender, según la enseñanza expresa de Kant, el contenido de la penúltima petición del Padrenuestro: «No nos dejes caer en la tentación». Escribe, en efecto, el filósofo en sus lecciones universitarias sobre filosofía moral: 
«A menudo uno se vanagloria de ser inocente, y que no ha sufrido la tentación, hay por ello causas de preservarse de toda tentación; de ahí que también Cristo haya enseñado en el Padrenuestro (...) a pedir que no se nos ponga en tentación. Pues ¿quién sabe cuánto alcanzan nuestras actitudes morales fundamentales (moralische Gesinnungen) y quién ha resistido ya todas las pruebas? El cielo conoce de modo insuperable nuestra culpa; ¿quién puede decir que es moralmente inocente?»(V-Mo/Collins, AA 27: 434).

$\mathrm{El}$ acto primero y fuera del tiempo por el que el hombre ha elegido libremente la máxima de subordinar la ley moral al amor propio ha tenido también consecuencias muy graves en la facultad humana de conocer el valor moral de nuestro propio corazón. El hombre es, en efecto, malo por naturaleza, en tercer lugar, porque en él habita «la falta de probidad consistente en engañarnos a nosotros mismos, que impide que arraigue en nosotros la auténtica actitud moral fundamental (echte moralische Gesinnung)»(RGV, AA 06: 29). Apartarse de este mal radical, de esta "propensión perversa al engaño disimulado (schlimmer Hang zur feinen Betrügerei)» (MpVT, AA 08: 271)), limpiarse esta «mancha pútrida de nuestra especie» (fauler Fleck unserer Gattung) (RGV, AA 06: 38) es precisamente, aunque Kant no lo haya llegado a decir de modo literal, lo que el orante pide en la última petición del Padrenuestro: «Líbranos del mal». Pues, como sí ha dejado dicho expresamente el filósofo respecto de nuestra tendencia a la mentira sobre nosotros mismos, «apartar esta propensión es tarea del carácter que el hombre ha de forjar en sí mismo» (MpVT, AA 08: 271). No se olvide que, en las más antiguas interpretaciones del Padrenuestro, el ruego «líbranos del mal» se entendía como la petición por la liberación del «maligno» ${ }^{8}$, esto es, de aquel a quien el propio Jesús llama «padre de la mentira» $(J n$ 8, 44). Sobre este asunto observa el propio Kant en La metafísica de las costumbres (MS, AA 06: 431): «Es curioso que la Biblia no se remonte al fratricidio (de Caín) como el primer delito por el que el mal ha entrado en el mundo, sino a la primera mentira (porque contra aquel se rebela la naturaleza) y que al autor de todo el mal lo llame el mentiroso desde el principio y el padre de la mentira».

Si la interpretación del pensamiento de Kant desarrollada en estas páginas es correcta, el Padrenuestro, es, en efecto, una oración plenamente moral, porque todas las peticiones que contiene se refieren o al fin de la vida moral o a

8 Vid. el monumental estudio de Santos SABugal, Abbá... La oración del Señor, Madrid, Caparrós Editores, 2007, $2^{\text {a }}$ ed., especialmente pp. 80-116. Como resumen de la interpretación patrística de la última petición del Padrenuestro, se lee en la última página citada: «La petición final suplica por la liberación del mal, identificado con el diablo (Tertuliano, Orígenes, Cirilo Jer., Gregorio Nis., Juan Cr., Quodvultdeus, Cirilo A., Pedro Cr., Narsés de Edesa, Pedro de L., antigua "expositio Missae Romanae"), Satanás (Teodoro M., Isidoro de Pelusio), el diablo y el pecado (Ambrosio), todos males (Teodoro M., Agustín, Cesáreo de Arlés, Ildefonso de Toledo, Sacr. Gelasiano, antigua exposición del Padrenuestro para los "competentes", a los que se suman las paráfrasis poéticas de G. A. V. Juvenco y C. Sedulio), maquinados por el enemigo diabólico (Cipriano, Agustín, Máximo C.), el cual es "el mal por excelencia" (Juan Cr., Pedro Cris.)». 
los medios, positivos y negativos, que hacen posible la consecución de ese fin. Se confirma así el parecer explícito del propio Kant según el cual quien, mediante el rezo del Padrenuestro vivifica su voluntad de hacerse un hombre bueno y servir así a Dios, podrá un día dejar de rezarlo: el éxito obtenido hará ya inútiles sus ruegos. "Quien ya ha hecho grandes progresos en el bien» - declara tajantemente Kant— «debe dejar de rezar» (Refl 8092, AA 19: 638). Es decir: quien no deja de orar según el espíritu debe dejar de orar según la letra9.

\section{Conclusión: el PadRenuestro como compendio de la Religión moral}

Del Padrenuestro dijo Tertuliano, en conocida fórmula, que era el compendio del todo el Evangelio: breviarium totius Evangelii (De oratione, 1, 6, PL 1, 1255). Parafraseando estas palabras, cabe decir que la interpretación moral del Padrenuestro propuesta por Kant constituye el epítome de toda la religión en los límites de la mera razón, esto es, de toda religión moral: breviarium totius intra terminos solius rationis religionis, i. e., totius moralis religionis.

Según la enseñanza de Kant, en efecto, el cristianismo, rectamente entendido, coincide por entero con la religión moral, cuya naturaleza cabe resumir en dos actitudes fundamentales: observancia estricta de la ley moral por mor de ella misma y esperanza en que Dios, en tanto que sabiduría suprema, concederá todo bien que no está en el poder de los seres racionales finitos. En el borrador de una carta a Johann Caspar Lavater, ya en la temprana fecha de finales de abril de 1775 , se lee esta confidencia de Kant: «Lo esencial y lo más excelente de la doctrina de Cristo es precisamente esto: que pone la suma de toda religión en ser honrado con todas las fuerzas, teniendo fe, es decir, una confianza incondicional, en que Dios suplirá el resto del bien que no está en nuestro poder»(Br AA 10: 180). Miradas a esta luz, las peticiones del Padrenuestro son, en verdad, tanto expresión del deseo, activo por nuestra parte, de cumplir la ley moral y apartar de nosotros el mal moral, cuanto manifestación de la esperanza de que Dios, al valorar nuestro esfuerzo, completará nuestras fuerzas alejando definitivamente el mal y trayéndonos el bien perfecto. La misma invocación "Padre nuestro que estás en los cielos» la interpreta Kant en este mismo sentido moral: los que rezan la oración de Jesús forman una familia «bajo un padre moral

9 Que para Kant el espíritu de la oración no debe abandonarse nunca lo ha visto bien Stephen R. Palmouist en su estudio «Kant's Critical Hermeneutic of Prayer», The Journal of Religion, 77 (1997), pp. 584-604. En la p. 598 se lee, en efecto: «Para Kant, llamar a alguien "hombre de oración" significaría que la conducta de vida de una persona está regida por el espíritu de oración. Y esto, a su vez, quiere decir que la persona necesitaría tener una "buena disposición" (es decir, una intención de acatar la ley moral todo el tiempo) y necesitaría considerar esta disposición como relacionada de alguna manera con un Ser Supremo moralmente orientado». Palmquist considera que hay razones para pensar que este es precisamente el caso del propio Kant. 
comunitario, aunque invisible (unter einem gemeinschaftlichen, obzwar unsichtbaren, moralischen Vater)» (RGV: AA 06: 102), esto es, bajo Dios en tanto que «soberano moral del mundo (moralischer Weltherrscher)» (RGV: AA 06: 99). La interpretación que propone Kant del Padrenuestro es por ello acaso la más pura y excelsa de entre todas aquellas que no reconocen, aunque acaso tampoco niegan, la filiación divina de quien la ha enseñado (cf. RGV, AA 06: 63).

No cabe ocultar, sin embargo, que este ensayo de exégesis del Padrenuestro que pone entre paréntesis su índole de oración revelada, para considerarlo exclusivamente «dentro de los límites de la mera razón», suscita algunas serias dificultades.

Según se ha sostenido tradicionalmente, para que haya oración es menester que se den tres requisitos: primero, que el orante se acerque a Dios, a quien ora; segundo, que pida algo; y tercero, que haya una razón para alcanzar lo que pide. Esta razón es, por parte de Dios, su propia santidad, y por parte del que ora, la acción de gracias (cf. Tomás de Aquino, Summa Theologiae, II-II, q. 83, a. 17 c). Ahora bien, no cabe que todas estas condiciones se cumplan en lo que Kant llama el «espíritu de la oración» ni en el Padrenuestro interpretado como oración puramente moral.

En primer lugar, en efecto, el carácter exclusivamente moral que han de tener las peticiones de la oración excluye de manera necesaria la posibilidad de la acción de gracias. Si lo único que cabe pedir a Dios es ser moralmente bueno, entonces no hay nada por lo que quepa dar gracias a Dios. Y ello por dos razones principales. Primera, porque Kant tiene por imposible que logremos un cabal conocimiento de nuestro auténtico valor moral. Es conocida la nota a pie de página de la Crítica de la razón pura en la que el filósofo consigna inequívocamente esta imposibilidad: «La moralidad propiamente dicha de las acciones (mérito y culpa), incluso la de nuestra propia conducta, permanece, por tanto, enteramente oculta para nosotros» (KrV, A 551/B 579). Segunda, porque, aun cuando se diera el imposible de que en algún caso supiéramos que hemos obrado de manera moralmente buena, nuestro agradecimiento por ello correría el riesgo de trastocar nuestra oración en un acto de arrogancia y enaltecimiento. Nuestra oración sería, en efecto, como la oración del fariseo de la conocida parábola de Jesús. El que dice a Dios en su interior: «¡Oh Dios!, te doy gracias porque no soy como los demás hombres: ladrones, injustos, adúlteros; ni tampoco como ese publicano» (Lc 18, 11), ese, según nos dice el mismo Maestro del Evangelio, no queda «justificado» (cf. Lc 18, 14), es decir, no hace oración en absoluto. El agradecimiento hacia Dios, pues, ha de quedar por completo excluido de la oración propia de la religión en los límites de la mera razón. Pero ¿no se cercena con ello una dimensión esencial de la oración? ¿Es verdad que nada se puede agradecer a Dios, porque lo único que se le puede pedir en la oración es nuestro mejoramiento moral, del que nada sabemos y todavía menos podemos vanagloriarnos?

Es de justicia advertir que, en cierto modo, Kant parece responder a esta objeción al reconocer expresamente al sentimiento de agradecimiento un lugar 
entre los sentimientos propiamente religiosos ${ }^{10}$. El hombre religioso, dice, en efecto, Kant, "cuando se encuentra rodeado de una bella naturaleza, en un goce tranquilo y sereno de su existencia, siente en sí mismo una necesidad de estar por ello agradecido a alguien», alguien que no puede ser sino, como también admite el propio filósofo, «una inteligencia moral» que sea "la causa de él y del mundo» (KU, AA 05, 445-6). La razón del agradecimiento no sería ya en este caso la concesión de un presunto mejoramiento moral, sino la misma "sensación moral» (moralische Empfindung), es decir, el hecho mismo de que somos seres morales, de que se nos ha concedido el don de poder ser juzgados a la luz del fin final de la creación del mundo.

Ante esta respuesta de Kant, hay que reparar, sin embargo, ante todo, en que semejante sentimiento de agradecimiento no está en absoluto vinculado con la oración de petición, cuyo ejemplo máximo es precisamente el Padrenuestro. No es un sentimiento de gratitud por una petición atendida, sino el reconocimiento por un don que en modo alguno hemos podido pedir, puesto que ese don entraña la posibilidad de toda petición: la libertad misma. Pero es también menester advertir que, según parece desprenderse de lo que afirma el propio Kant, este sentimiento de agradecimiento, que es "por lo menos posible» (KU, AA 05:446), es también, necesariamente, un deber de virtud (cf. MS, AA 06: 454-5). Y en este punto cabría preguntarse si la concepción ética del filósofo no excluye que un estado sentimental sea el fundamento del reconocimiento de un deber y aun motor necesario para su observancia. A mayor abundamiento, nuestro deber de estar agradecidos a Dios no podría ser ya, según la distinción del propio Kant, un deber de agradecimiento "activo» (thätige Dankbarkeit), puesto que no agradecemos un beneficio (Wohltat), sino un deber de agradecimiento "meramente afectivo» o emocional (bloss affectionelle Dankbarkeit), ya que nuestra gratitud tendría por objeto «una mera benevolencia cordial del otro sin consecuencias físicas» (ein bloßes herzliches Wohlwollen des Anderen ohne physische Folgen) (MS, AA 06: 455).

En segundo lugar, según las enseñanzas de Kant, ni en la oración en general ni en el Padrenuestro en particular nos relacionamos realmente con Dios, sino solo con la idea de Dios. Es verdad que el uso práctico puro de la razón nos conduce necesariamente a postular la existencia de Dios, y aun a pensarlo como la suprema persona moral. Con ello, sin embargo, no quedamos autorizados en modo alguno, según advierte Kant, a pensar que en la oración entramos en relación personal con el ser de Dios, ni siquiera en la oscuridad de la fe moral. Al rezar el Padrenuestro nos quedamos, más bien, recluidos en nuestra propia razón pura práctica y sus exigencias: nada más digno que ellas hay y a ninguna otra cosa hemos de someternos. En sus papeles póstumos Kant se expresó sobre estas cuestiones con meridiana claridad, extrayendo las consecuencias

10 Sobre la cuestión de los sentimientos religiosos en la filosofía de Kant puede consultarse la contribución de BERnd Dörflinger, «Kants Kritik religiöser Gefühle», en NorberT FIscheR und JAKUB SIROvátKa (Hrsg.), Vernunftreligion und Offenbarungsglaube. Zur Erörterung einer seit Kant verschärften Problematik, Freiburg-Basel-Wien, Herder, 2015, pp. 219-231. 
últimas de su filosofía: «No es Dios un ser fuera de mí, sino simplemente un pensamiento en mí. Dios es la razón práctico-moral que se da leyes a sí misma. Por eso, Dios no existe más que en mí, en torno a mí y sobre mí» (OP, AA 21: $145)^{11}$. Pero, ¿es realmente posible mantenerse en el bien, luchar contra el mal y conservar la confianza en que Dios otorgará lo que no podemos lograr por nosotros mismos cuando se ha cercenado la raíz de donde podría proceder la fuerza y la esperanza? ¿Podrá el hombre en este «hablar en sí mismo y propiamente consigo mismo» (RGV, AA 06: 197) anclar con alguna seguridad la esperanza de su salvación? ¿Podrá un Dios que en último término no es más que la mera razón práctica pura redimir efectivamente al hombre? ¿Podrá la simple idea moral de Cristo como personificación del principio bueno, encarnado ya desde el comienzo en la naturaleza humana, abrir «la puerta de la libertad» a todos los que quieren dejar de estar atados con las cadenas del mal? (RGV, AA 06: 82).

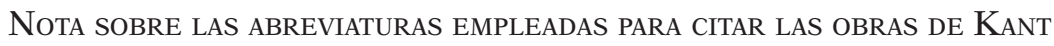

AA, Akademie Ausgabe. Kant's gesammelte Schriften, hrsg. von der Deutschen Akademie der Wissenschften zu Berlin, Berlin, 1902 ss. (En cada caso se indica el volumen y el número de la página, con la sola excepción de las referencias a la Kritik der reinen Vernunft que, como es usual, se cita según la paginación original de la primera y la segunda ediciones, señaladas respectivamente con las letras A y B).

$\mathrm{Br}$, Briefe

$\mathrm{KpV}$, Kritik der praktischen Vernunft

$\mathrm{KrV}$, Kritik der reinen Vernunft

KU, Kritik der Urteilskraft

MpVT, Über das Mißlingen aller philosophischen Versuche in der Theodicee

MS, Die Metaphysik der Sitten

11 Cf. también estos otros pasajes del Opus Postumum, entre los muchos que cabría citar al respecto: «El sujeto del imperativo categórico de la razón, no técnico-práctica, sino práctico-moral: un ideal trasc(endental) procedente de la fil(osofía) trasc(endental) como proposición sintética a priori de un concepto puro (no de la intuición sensible), es Dios. Que un ser tal exista no se puede negar: pero tampoco se puede afirmar que exista fuera del hombre que piensa racionalmente. En él (en el hombre que piensa moralmente, según mandatos del deber de nosotros mismos) vivimos (sentimus), urdimos nuestra vida (agimus) y somos (existimus)» (OP, AA 22, 55). "La proposición "Dios existe" no dice más que: en la razón humana, que se determina moralmente a sí misma, existe un principio supremo que se determina a sí mismo, y el hombre se ve obligado a obrar sin desaliento en conformidad con tal principio» (OP, AA 21, 146). «El entero Decálogo no apunta aquí a una sustancia, sino solo a una idea de la ley, (siendo) esta última la razón misma del hombre, que, a este respecto, es un ser natural» (OP, AA 21, 49). Vid. Rogelio Rovira, Teología Ética. Sobre la fundamentación y construcción de una Teología racional según los principios del idealismo trascendental de Kant. Madrid, Ediciones Encuentro, 1986. Cf. también Gerhard Schwarz, Est Deus in nobis. Die Identität von Gott und reiner praktischer Vernunft in Immanuel Kants "Kritik der praktischen Vernunft», Berlin, Verlag TU Berlin, 2004. 
OP, Opus Postumum

Refl, Reflexionen

RGV, Die Religion innerhalb der Grenzen der bloßen Vernunft

SF, Der Streit der Fakultäten

VARGV, Vorarbeit zur Religion innerhalb der Grenzen der bloßen Vernunft

V-Mo/Collins, Moralphilosophie Collins

V-Met-K2/Heinze, Metaphysik K2 (Heinze)

V-MS/Vigil, Die Metaphysik der Sitten Vigilantius

Facultad de Filosofía de la Universidad Complutense de Madrid Instituto Universitario de Ciencias de las Religiones

Rogelio RoviRA rrovira@ucm.es

[Artículo aprobado para publicación en diciembre de 2015] 